\title{
PENGARUH PENERAPAN MODEL PEMBELAJARAN SAINS TEKNOLOGI MASYARAKAT (STM) TERHADAP KEMAMPUAN LITERASI SAINS SISWA PADA MATERI LARUTAN ELEKTROLIT DAN NON ELEKTROLIT
}

\author{
Noprima Yulika'), Lisa Utami2) \\ Universitas Islam Negeri Sultan Syari Kasim Riau \\ Program Studi Pendidikan Kimia, Fakultas Tarbiyah dan Keguruan, Pekanbaru \\ e-mail:*1noprimayulika@yahoo.com, ${ }^{2}$ |1154.lazoelva@yahoo.com
}

\begin{abstract}
Abstrak
Literasi sains merupakan kapasitas untuk menggunakan pengetahuan ilmiah, mengidentifikasi pertanyaan-pertanyaan, dan menarik kesimpulan berdasarkan fakta, bukti dan data yang ada agar dapat memahami dan membantu peneliti untuk membuat keputusan tentang dunia alam dan interaksi manusia dengan alamnya. Penelitian ini bertujuan untuk mengetahui pengaruh model pembelajaran Sains Teknologi Masyarakat (STM) terhadap kemampuan Literasi Sains siswa pada materi larutan elektrolit dan non elektrolit di SMA Negeri 2 Tambang. Bentuk penelitian yang digunakan dalam penelitian ini adalah quasy experiements, dengan desain penelitian non equivalent control group design. Pengambilan sampel menggunakan teknik purpossive sampling. Data diperoleh melalui tes, dan wawancara. Hasil penelitian menunjukkan bahwa nilai Sig. (2-tailed) yang didapat sebesar 0,000 yang mana lebih kecil dari $0,05(0,000<0,05)$, dan thitung lebih besar dari pada ttabel $(11,564>1,667)$ maka sebagaimana dasar pengambilan keputusan dalam uji independent sample t-test dapat disimpulkan bahwa Ha diterima dan Ho ditolak. Berarti terdapat pengaruh model pembelajaran Sains Teknologi Masyarakat (STM) terhadap kemampuan literasi sains siswa pada materi larutan elektrolit dan non elektrolit di SMA Negeri 2 Tambang, dengan koefisien pengaruh (Kp) sebesar 18,2\%.
\end{abstract}

Kata Kunci: Model Pembelajaran Sains Teknologi Masyarakat (STM), Literasi Sains, Larutan Elektrolit dan Non Elektrolit.

\begin{abstract}
Science literacy was the capacity to use scientific knowledge, to identify questions, to draw a conclusion based on the facts, evidence, and data in order to understand and help researchers to make decisions about the natural world and human interactions with the nature. This research aimed at knowing the effect of implementing Science, Technology, and Society (STS) learning model toward student science literacy ability on Electrolyte and non-Electrolyte Solution lesson at State Senior High School 2 Tambang. It was a quasi-experimental research with non-equivalent control group design. Purposive sampling technique was used in this research. The data were obtained from test and interview. The research findings showed that the score of Sig. (2-tailed) 0.000 was smaller than 0.05 (0.000<0.05), and tobserved was higher than ttable (11.564>1.667). Based on the basis for decision making in Independent Sample t- test, it could be concluded that Ha was accepted and HO was rejected. It meant that there was an effect of implementing STS learning model toward student science literacy ability on Electrolyte and non- Electrolyte Solution lesson at State Senior High School 2 Tambang with the coefficient of effect $18.2 \%$.
\end{abstract}

Keywords:Science, Technology, and Society (STS) Learning Model, Science Literacy, 


\section{Pendahuluan}

Sains berkaitan dengan cara mencari tahu tentang alam secara sistematis, penguasaan kumpulan pengetahuan yang berupa fakta-fakta, konsep-konsep atau prinsip-prinsip serta merupakan suatu proses penemuan. Pendidikan untuk literasi sains dibutuhkan untuk mengajarkan konsep ilmu dan teori serta belajar tentang sifat yang terdapat pada konsep-konsep dan bagaimana mereka berfungsi berkaitan dengan keyakinan lain tentang dunia fisik. Berdasarkan pendapat-pendapat tersebut, pendidikan di Indonesia masih jauh dari kata mendekati dengan literasi sains (Yuliana,

D. Cahyani dan E. Roviati, 2016).

Pembelajaran hendaknya diarahkan untuk mengembangkan individu yang berliterasi sains (scientifically literate). Literasi sains penting dan menjadi kebutuhan setiap individu karena kemampuan literasi sains suatu negara berhubungan erat dengan tingkat ekonomi di negara tersebut (S. Windyariani,2017). Literasi sains penting untuk dimiliki oleh siswa karena bisa mengembangkan beberapa kemampuan diri, salah satunya yaitu berdasarkan konsep yang telah dipahami siswa mampu menjelaskan fenomena yang terjadi, serta mampu menggunakan metode ilmiah untuk memecahkan masalah yang terjadi disekitarnya. Secara garis besar, literasi sains memiliki makna siswa dapat menggunakan konsep-konsep keilmuwan yang telah diperoleh untuk memecahkankan masalah yang terjadi dalam kehidupan sehari-hari (Aisyah dan K. Dwiningsih, 2017).

Literasi yang dimiliki siswa Indonesia saat ini masih sangat rendah, hal ini dibuktikan oleh hasil hasil Studi Programme For International Students Assesment of Student (PISA) (L. Nahdiah dan mahdian, 2017). Hasil dari penilaian PISA yang dilakukan dari tahun 2000 pun tidak menunjukkan hasil yang gemilang karena skor ratarata siswa masih jauh dibawah rata-rata internasional yaitu pada skor 500. Dalam hal ini, pada tahun 2000 nilai rata-rata sains siswa Indonesia adalah 371, 382 pada 2003, dan 393 pada 2006. Hasil PISA 2015, negara Indonesia berada pada peringkat 10 besar terbawah yaitu peringkat 62 dari 70 negara dengan rata-rata skor 403 (U. Toharudin, 2011).

Berdasarkan hasil observasi yang telah peneliti lakukan di SMA Negeri 2 Tambang, diperoleh informasi bahwa hasil belajar siswa masih banyak yang di bawah standar 
ketuntasan dari Kriteria Ketuntasan Minimal (KKM) yang telah ditetapkan oleh sekolah untuk mata pelajaran kimia, yaitu 70 dan siswa masih cenderung pasif, hanya mencatat yang disampaikan guru tanpa ada respon balik terhadap yang dicatat atau disampaikan guru sehingga berdampak pada kemampuan siswa dalam memahami konsep yang diajarkan. Hal ini disebabkan oleh kemampuan literasi sains siswa yang masih rendah, untuk itu guru dituntut agar menggunakan metode-metode yang tepat dengan materi yang diberikan kepada siswa agar hasil pembelajaran mencapai tujuan seperti yang diharapkan. Untuk mengatasi masalah belajar siswa tersebut perlu dibutuhkan suatu perubahan pendekatan dalam pembelajaran, salah satunya yaitu dengan menggunakan pendekatan STM.

Secara garis besar model pembelajaran STM memiliki hal-hal penting dimana setiap tahapannya memiliki tujuan tertentu. Tujuan dari pembelajaran STM adalah untuk membentuk individu yang memiliki literasi sains dan teknologi serta mempunyai kepedulian terhadap masalah masyarakat dan lingkungannya(M. Rachmawati dan S. Admoko, 2017). Model pembelajaran STM yaitu salah satu model yang memberikan pengalaman langsung bagi siswa, karena pembelajarannya mengangkat isu atau masalah yang sedang terjadi di masyarakat sebagai topik dalam pembelajaran, sehingga siswa bisa merasakan pembelajaran yang bermakna, karena di dalam pembelajarannya siswa didorong untuk menggunakan keterampilan proses sains dalam memecahkan masalah yang sedang terjadi di masyarakat (Nurjanah, 2016).

Kekhasan dari model ini adalah pada tahap inisiasi atau memulai yang disebut juga dengan invitasi yaitu undangan agar siswa memusatkan perhatian pada pembelajaran, yang mana pada pendahuluan dikemukakan isu-isu atau masalah yang ada dimasyarakat yang dapat digali dari siswa, tetapi apabila guru tidak berhasil memperoleh tanggapan dari siswa dapat saja dikemukakan oleh guru sendiri.

Apersepsi dalam kehidupan juga dapat dilakukan, yaitu mengaitkan materi yang akan dibahas dengan peristiwa yang telah diketahui oleh siswa, sehingga terlihat adanya kesinambungan pengetahuan, karena diawali dengan hal-hal yang telah diketahui siswa yang sebelumnya yang ditekankan pada keadaan yang ditemui dalam keadaan seharihari. Dengan kata lain, model pembelajaran STM ialah suatu model pembelajaran yang mengaitkan antara sains dan teknologi serta pemanfaatanya bagi masyarakat $(\mathrm{H}$. 
Lestari, S. Ayub dan Hikmawati, 2016).

Salah satu materi yang sesuai dengan model pembelajaran Sains Teknologi Masyarakat adalah materi larutan elektrolit dan non elektrolit yang memiliki karakteristik menuntut siswa agar bisa merancang dan melakukan percobaan yang telah dirancangnya untuk menemukan konsep pada pokok bahasan larutan elektrolit dan non elektrolit serta pada materi tersebut terdapat isu atau masalah yang ada dalam kehidupan sehari-hari sehingga siswa bisa membedakan berbagai jenis larutan dan menemukan penyebab perbedaan kemampuan berdasarkan daya hantar listriknya.

Penerapan model pembelajaran STM untuk meningkatkan literasi sains siswa dalam pembelajaran sudah dilakukan oleh Setyo Admoko dan Maulida rachmawati. Yaitu terjadi peningkatan literasi sains secara signifikan ketika kegiatan pembelajaran dengan model pembelajaran STM pada kelas eksperimen 1 dan eksperimen 2 telah diterapkan. Nilai rata-rata N-Gain tiap kompetensi dari kedua kelas dalam kategori sedang. Adapun perbedaan antara penelitian yang dilakukan peneliti adalah terletak pada materi dan jenis penelitian yang digunakan, yaitu materi larutan elektrolit dan non elektrolit dan jenis penelitian quasy eksperimen dengan desain non-equivalent group desaign (M. Rachmawati dan S. Admoko, 2017).

\section{Metode}

Penelitian ini menggunakan metode quasy eksperimen. Desain yang digunakan yaitu non equivalent control group design (Sugiono, 2014). Populasi dalam penelitian ini yaitu seluruh siswa kelas X MIA SMA Negeri 2 Tambang Tahun Ajaran 2019/2020 yang berjumlah 177 siswa. Teknik pemilihan sampel dalam penelitian ini adalah dengan menggunakan teknik purpossive sampling yaitu teknik sampling yang digunakan oleh peneliti jika peneliti menggunakan pertimbangan-pertimbangan tertentu didalam pengambilan sampelnya (S. Arikunto, 2009).

Pengumpulan data yang digunakan dalam penelitian ini adalah tes kemampuan literasi sains dan wawancara. Tes kemampuan literasi sains yang digunakan adalah soal essay sebanyak 5 soal pada pokok bahasan larutan elektrolit dan non elektrolit.

Penelitian dilakukan terhadap dua kelas yang homogen, Kedua kelas tersebut terlebih dahulu diberi pretest untuk mengetahui sejauh mana materi yang akan diajarkan telah 
dapat dikuasai oleh siswa. Pada kelas eksperimen diberikan perlakuan menggunakan model pembelajaran STM sedangkan kelas kontrol dengan pendekatan saintifik. kemudian Setelah diberi perlakuan kedua kelas dilakukan posttest.

Hasil dan Pembahasan

Data awal atau pretest diambil dari hasil tes kemampuan literasi sains siswa pada kelas eksperimen dan kontrol sebelum dilakukannya treatment yang terangkum menggunakan SPSS versi 22 dalam tabel 1 berikut.

Tabel 1. Deskripsi data pretest dari hasil tes kemampuan literasi sains kelas eksperimen dan kontrol

\begin{tabular}{llllll}
\hline Kelas & $\mathrm{N}$ & Minimum & Maximum & Mean & $\begin{array}{l}\text { Std. } \\
\text { Devation }\end{array}$ \\
\hline Eksperimen & 34 & 55 & 75 & 63,24 & 6,015 \\
\hline Kontrol & 35 & 45 & 65 & 55,14 & 6,001 \\
\hline
\end{tabular}

Berdasarkan Tabel 1, di atas menujukkan perbandingan nilai pretest dari kelas eksperimen dan kontrol. Nilai pada kelas eksperimen lebih tinggi dari pada kelas kontrol, baik nilai minimum maupun nilai maksimum serta nilai rata-rata pretest siswa.

Data nilai posttest dari kelas eksperimen dan kelas kontrol diperoleh berdasarkan hasil tes kemampuan literasi sains siswa setelah dilakukannya treatment yang terangkum dengan menggunakan SPSS versi 22 pada tabel 2.

Tabel 2. Deskripsi data posttest dari hasil tes kemampuan literasi sains kelas eksperimen dan kontrol

\begin{tabular}{llllll}
\hline Kelas & $\mathrm{N}$ & Minimum & Maximum & Mean & Std. Devation \\
\hline Eksperimen & 34 & 75 & 90 & 82,50 & 4,308 \\
\hline Kontrol & 35 & 50 & 75 & 66.00 & 7,154
\end{tabular}

Berdasarkan Tabel output diatas juga menujukkan perbandingan nilai posttest dari kelas eksperimen dengan kelas kontrol. Nilai pada kelas eksperimen lebih besar daripada kelas kontrol, baik nilai minimum maupun nilai maksimum serta nilai rata-rata posttest siswa. 
Rumus uji independent sample t-test digunakan untuk menguji hipotesis. Hasil Uji ttest terangkum dalam tabel 3 berikut.

Tabel 3. Hasil analisis uji independent sample t-test

\begin{tabular}{ccccc}
\hline & & \multicolumn{3}{c}{$\mathrm{t}$-test for equality of means } \\
\cline { 3 - 5 } & & $\mathrm{t}$ & $\mathrm{Df}$ & Sig. (2-tailed) \\
\hline Hasil Kemampuan & $\begin{array}{c}\text { Equal variances } \\
\text { Literasi Sains Siswa }\end{array}$ & 11.564 & 67 & 0,000 \\
\hline
\end{tabular}

Berdasarkan Tabel Output diatas diketahui nilai Sig. (2-tailed) sebesar 0,000 yang mana lebih kecil dari $0,05(0,000<0,05)$, dan thitung lebih besar dari pada ttabel $(11,564>1,667)$ maka sebagaimana dasar pengambilan keputusan dalam uji independent sample t-test dapat disimpulkan bahwa Ha diterima dan Ho ditolak.

Berdasarkan data hasil uji "t", dapat juga diketahui derajat peningkatan hasil kemampuan literasi sains siswa yaitu dengan menghitung koefisien $\left(r^{2}\right)$ sementara untuk mengetahui koefisien pengaruh (Kp) menggunakan rumus $\mathrm{Kp}=\mathrm{r}^{2} \times 100 \%$.

Tabel 4. Uji $r^{2}$ dan Kp.

\begin{tabular}{ll}
\hline$r^{2}$ & $K p$ \\
\hline 0,427 & $18,2 \%$
\end{tabular}

Berdasarkan tabel tersebut dapat disimpulkan bahwa terdapat pengaruh sebesar $18,2 \%$.

Kemampuan literasi sains siswa perindikator dapat diketahui dari besarnya persentase jawaban yang diberikan siswa pada setiap soalnya pada tabel 5 .

Tabel 5. Perbandingan persentasi kemampuan literasi sains siswa

\begin{tabular}{|c|c|c|c|c|}
\hline \multirow[t]{2}{*}{ No } & \multirow[t]{2}{*}{ Indikator } & \multirow{2}{*}{$\begin{array}{l}\text { No } \\
\text { Soal }\end{array}$} & \multicolumn{2}{|c|}{$\begin{array}{c}\text { Persentase Kemampuan Literasi } \\
\text { Sains }\end{array}$} \\
\hline & & & Kontrol & Eksperimen \\
\hline 1 & $\begin{array}{c}\text { Literasi } \\
\text { Fungsional }\end{array}$ & $2,4,5$ & $69,33 \%$ & $84,33 \%$ \\
\hline 2 & $\begin{array}{c}\text { Literasi } \\
\text { Konseptual }\end{array}$ & 1,3 & $66,5 \%$ & $82 \%$ \\
\hline
\end{tabular}


Rata-rata

$67,91 \%$

$83,16 \%$

Dari Tabel 5 dapat dijelaskan bahwa persen kemampuan literasi sains siswa kelas eksperimen lebih tinggi dibandingkan kelas kontrol. Perbedaan ini dipengaruhi oleh keaktifan siswa dalam belajar. Selain hal tersebut juga dipengaruhi oleh faktor eksternal dan internal seperti yang di sampaikan oleh Eka Nurul Qomaliyah dkk dalam penelitiannya menjelaskan bahwa faktor eksternal berhubungan dengan faktor belajar, fasilitas, model yang diterapkan disekolah atau perhatian orang tua dan faktor masyarakat yang berhubungan dengan keadaan lingkungan yang mendukung atau tidaknya siswa untuk mengikuti pembelajaran di sekolah. Faktor internal berhubungan dengan kondisi fisik dan psikologi siswa dalam mengikuti pembelajaran. (E. N. Qomaliyah, 2016).

Soal tes literasi sains yang memiliki tingkat kesukaran yang tinggi berpengaruh terhadap lembar jawaban siswa, siswa ada yang mampu menjawab ada yang tidak. Model pembelajaran STM ini dapat meningkatkan kemampuan litearsi sains siswa, sebab dalam pembelajarannya menggunakan sumber belajar yang beragam. Sumber belajar tersebut adalah buku paket siswa, LKPD yang diberikan oleh guru dan juga internet yang bisa di akses oleh siswa sehingga siswa dalam diskusi kelompok bisa baerbagi tugas untuk mencari data dari sumber-sumber belajar tersebut. Partisipasi aktif siswa dalam penerapan model ini juga meningkatkan penasaran siswa karena siswa diberi kesempatan untuk menemukan, menggali, dan mencari tahu berbagai aplikasi sains yang ada disekitarnya, hingga siswa dapat menyadari bahwa kimia adalah ilmu pengetahuan yang dekat dengan kehidupan sehari-hari..

Model ini juga dapat melatih kemampuan berpikir siswa yaitu berpikir analitis untuk menyelesaikan suatu permasalahan disetiap pertemuan. Berdasarkan tahapan orientasi pembelajaran yaitu tahap apersepsi, pembentukan konsep, aplikasi konsep, pemantapan konsep dan evaluasi. Tahapan ini sesuai dengan kaidah metode ilmiah, sehingga dapat mengembangkan kemampuan berpikir analisis dan logis. Siswa menganalisis permasalahan dan memilih serta data atau mengumpulkan informasi yang mendukung pemecahan masalah dalam 
pembelajaran, hal ini sesuai dengan penelitian Eka Nurul Qomaliyah dkk (E. N. Qomaliyah, 2016).

Model pembelajaran STM dapat melatih siswa untuk mengembangkan kemampuan kerja sama, berpikir dan mempermudah siswa untuk belajar. Penelitian ini senada dengan penelitian yang dilakukan Yuvita Ayuningtyas, dkk bahwa hasil analisis data penelitian yang sudah dilakukannya bisa dilihat dari kemampuan literasi sains siswa di kelas eksperimen lebih tinggi daripada kelas kontrol. Rata-rata nilai hasil belajar kognitif pada kelas eksperimen menggunakan model pembelajaran STM yaitu 88,79 sementara pada kelas control 80,06 (Y. Ayuningtyas,2020). Demikian pula dengan penelitian yang dilakukan oleh Nur Avita Sari bahwa nilai rata-rata indikator literasi sains sebesar $84,57 \%$ (N. A. Sari, 2017). seseorang yang memiliki keterampilan literasi sains mempunyai kemampuan memecahkan masalah menggunakan konsep- konsep sains yang didapat dalam pendidikan sesuai dengan jenjangnya dan dapat memanfaatkan teknologi yang ada dalam kehidupan seharihari (Y. Rahmadani, 2018).

\section{Kesimpulan}

Berdasarkan hasil penelitian, dapat disimpulkan bahwa ada pengaruh penerapan model pembelajaran Sains Teknologi Masyarakat (STM) terhadap kemampuan literasi sains siswa pada materi larutan elektrolit dan non elektrolit di SMA Negeri 2 Tambang yaitu sebesar 18,2\%. Kemampuan literasi sains siswa pada kelas eksperimen lebih tinggi daripada kemampuan literasi sains siswa pada kelas kontrol sehingga bisa dikatakan bahwa penggunaan model pembelajaran Sains Teknologi Masyarakat berpengaruh terhadap kemampuan literasi sains siswa.

\section{Daftar Referensi}

Aisyah dan Kusumawati Dwiningsih, (2017). Pengembangan Lembar Kegiatan Siswa (LKS) Berorientasi Literasi Sains pada Materi Larutan Elektrolit dan Non Elektrolit. UNESA Journal of Chemical Education, 6(2), 330.

Arikunto, S. 2009. Dasar-dasar Evaluasi Pendidikan. Jakarta: Bumi Aksara. 
Ayuningtyas, Y. dkk. (2020). Pengaruh Model Pembelajaran Sains Teknologi Masyarakat (STM) dalam Meningkatkan Kemampuan Literasi Sains Siswa di MTsN 1 Konsel. Jurnal Kulidawa, 1(1), 41.

Lestari, H., S. Ayub dan Hikmawati. (2016). Penerapan Model Pembelajaran Sains Teknologi Masyarakat (STM) Untuk Meningkatkan Hasil Belajar Fisika Siswa Kelas VIII SMPN 3 Mataram. Jurnal Pendidikan Fisika dan Teknologi, 2(3), 112.

Nahdiah, L., Mahdian dan A. Hamid. (2017). Pengaruh Model Pembelajaran Peer Led Guided Inquiry (PLGI) Terhadap Literasi Sains dan Hasil Belajar Siswa pada Materi Hidrolisis Garam Siswa Kelas XI Kimia SMAN 3 Banjarmasin. Journal Of Chemistry And Education, 1(1), 74.

Nurjanah, R. L. Panjaitan, dan D. Kurnia. (2016). Pengaruh Model Sains Teknologi Masyarakat Terhadap Hasil Belajar Siswa Kelas V Pada Materi Peristiwa Alam. Jurnal Pena Ilmiah, 1(1), 834.

OECD, 2016, PISA Result: Result-in-focus, (Online) Tersedia: https://www.oecd.org/pisa/pisa-2015-results-in-focus.pdf. Diakses 30 November 2019.

Qomaliyah, E. N., Sukib, dan I. N. Loka. (2016). Pengaruh Model Pembelajaran Inkuiri Terbimbing Berbasis Literasi Sains Terhadap Hasil Belajar Materi Pokok Larutan Penyangga. Jurnal Pijar MIPA, 11(2). 108-109.

Rachmawati, M. dan S. Admoko. (2017). Penerapan Model Pembelajaran Sains Teknologi Masyarakat Untuk Meningkatkan Literasi Sains Siswa SMK Negeri 3 Bojonegoro Kelas X Teknik Pemesinan Pada Materi Fluida Statis. Jurnal Inovasi Pendidikan Fisika (Jipf), 6(3), 92.

Rahmadani, Y. dkk. (2018). Profil Keterampilan Literasi Sains Siswa Sekolah Menengah Atas (SMA) di Karanganyar. Jurnal Pendidikan Biologi, 7(3), 184.

Sari, N. A. (2017). Kepraktisan dan Efektivitas LKS Berbasis Inkuiri Untuk Melatih Literasi Sains Pada Materi Sistem Pernapasan di Kelas XI. Jurnal Universitas Negeri Surabaya, 6(1), 17.

Sugiono. 2014. Metode Penelitian Pendidikan Pendekatan Kuantitatif, Kualitatif, dan $R \& D$. Bandung: Alfabeta. 
Toharudin, U., S. Henrawati, dan Arustaman. 2011. Membangun Literasi Sains Peserta Didik. Bandung: Humaniora Mencerahkan Kehidupan.

Windyariani, S. dan Windyariani. (2017). Pembelajaran IPA Dengan Praktikum Berbasis Konteks dan Literasi Sains: Perspektif Guru SD di Sukabumi. Jurnal Pendidikan Matematika dan IPA, 8(1), 23

Yuliani, D. Cahyani dan E. Roviati. (2016). Penerapan Pembelajaran Ipa Berbasis Keterampilan Proses Sains Untuk Meningkatkan Literasi Sains Pada Mata Pelajaran IPA Di Kelas VII Materi Pokok Pencemaran Lingkungan Di SMPN 1 Cikijing. Jurnal Sains dan Pendidikan Sains, 5(2), 122-123. 